https://helda.helsinki.fi

\title{
Vitamin C for treating atrial fibrillation : [Protocol]
}

\section{Hemilä, Harri Olavi}

2015-01-14

Hemilä , H O \& Suonsyrjä , T J 2015 , ' Vitamin C for treating atrial fibrillation : [Protocol] ' ,

Cochrane database of systematic reviews , no. 1 , CD011471 . https://doi.org/10.1002/14651858.CD011471

http://hdl.handle.net/10138/250566

https://doi.org/10.1002/14651858.CD011471

publishedVersion

Downloaded from Helda, University of Helsinki institutional repository.

This is an electronic reprint of the original article.

This reprint may differ from the original in pagination and typographic detail.

Please cite the original version. 


\section{(A) Cochrane Library}

Cochrane Database of Systematic Reviews

\section{Vitamin C for treating atrial fibrillation (Protocol)}

Hemilä H, Suonsyrjä T

Hemilä H, Suonsyrjä T.

Vitamin C for treating atrial fibrillation.

Cochrane Database of Systematic Reviews 2015, Issue 1. Art. No.: CD011471.

DOI: 10.1002/14651858.CD011471.

www.cochranelibrary.com 
TABLE OF CONTENTS

HEADER . . . . . . . . . . . . . . . . . . . . . . . . . . . . . . . . . . . . 1

ABSTRACT . . . . . . . . . . . . . . . . . . . . . . . . . . . . . . . . . . . . . . . . . .

BACKGROUND . . . . . . . . . . . . . . . . . . . . . . . . . . . . . . . . . . . .

OBJECTIVES . . . . . . . . . . . . . . . . . . . . . . . . . . . . . . . . . . . . . . .

METHODS . . . . . . . . . . . . . . . . . . . . . . . . . . . . . . . . . . . . . . . .

ACKNOWLEDGEMENTS . . . . . . . . . . . . . . . . . . . . . . . . . . . . . . . . . . . . . . . .

REFERENCES . . . . . . . . . . . . . . . . . . . . . . . . . . . . . . . . . . . . . 6

APPENDICES . . . . . . . . . . . . . . . . . . . . . . . . . . . . . . . . . . . . . 10

CONTRIBUTIONS OF AUTHORS . . . . . . . . . . . . . . . . . . . . . . . . . . . . . . . . . . . . . . . . . . . .

DECLARATIONS OF INTEREST . . . . . . . . . . . . . . . . . . . . . . . . . . . . . . . . 11

SOURCES OF SUPPORT . . . . . . . . . . . . . . . . . . . . . . . . . . . . . . . . . . . . . . . . . . 


\title{
[Intervention Protocol]
}

\section{Vitamin C for treating atrial fibrillation}

\author{
Harri Hemilä ${ }^{1}$, Timo Suonsyrjä ${ }^{2}$ \\ ${ }^{1}$ Department of Public Health, POB 41, University of Helsinki, Helsinki, Finland. ${ }^{2}$ Emergency Clinic, Helsinki University Central \\ Hospital, Meilahti Hospital, Helsinki, Finland \\ Contact address: Harri Hemilä, Department of Public Health, POB 41, University of Helsinki, Mannerheimintie 172, Helsinki, FIN- \\ 00014, Finland. harri.hemila@helsinki.fi.
}

Editorial group: Cochrane Heart Group.

Publication status and date: New, published in Issue 1, 2015.

Citation: Hemilä H, Suonsyrjä T. Vitamin C for treating atrial fibrillation. Cochrane Database of Systematic Reviews 2015, Issue 1. Art. No.: CD011471. DOI: 10.1002/14651858.CD011471.

Copyright (C) 2015 The Cochrane Collaboration. Published by John Wiley \& Sons, Ltd.

\begin{abstract}
A B S T R A C T
This is the protocol for a review and there is no abstract. The objectives are as follows:

To assess the efficacy of vitamin $\mathrm{C}$ for treating AF, and for the secondary prevention of AF.
\end{abstract}

\section{B A C K G ROU N D}

\section{Description of the condition}

Atrial fibrillation (AF) is the most common sustained arrhythmia encountered in clinical practice and contributes substantially to cardiac morbidity and mortality (Lip 2012; Page 2004). Prevalence of $\mathrm{AF}$ increases with age from about $0.1 \%$ among adults under 55 years to about $10 \%$ in people aged over 80 years (Go 2001; Kirchof 2012).

AF is characterized by rapid and irregular activation of the atrium at a rate of $>300$ pulses of the atrium muscular wall per minute (Lip 2012). This is much higher than the rate when the heart is in normal sinus rhythm (SR). In AF the ventricular rate is determined by the interaction between atrial rate and the filtering function of the atrioventricular node; and the ventricular rate may be about 150 beats per minute (bpm).

AF can cause palpitations, dyspnea, fatigue, light-headedness and syncope (brief loss of consciousness, or 'fainting') (Page 2004). The more severe consequences of AF are thromboemboli (blood clots which form in the blood vessels then circulate to other areas of the body) and congestive heart failure (HF). AF may lead to stasis (stagnation) of blood in the atria and clot formation, which may further lead to thromboemboli. Owing to this, AF increases the risk of stroke by five fold (Kannel 1998; Kirchof 2012). AF may also lead to overload on the heart and thereby to HF. Thus, AF is both a cause for, and a result of HF (Wang 2003).

There are over 30 causes for AF, which can be divided into cardiovascular and non-cardiovascular causes (Iqbal 2005). Due to the high frequency in community, hypertension is the most common risk factor for $\mathrm{AF}$ and explains over $10 \%$ of cases (Kannel 1998; Kirchof 2012). 'Lone AF' is a term used to describe cases who have no identifiable causes, thus 'lone AF' is a diagnosis based on exclusions (Kozlowski 2009). A further approach to classifying AF is by temporal basis to paroxysmal (self terminating), persistent (lasts > 7 days or requires cardioversion) and permanent (Page 2004). AF can be triggered by various acute stressful conditions. About $30 \%$ of patients in cardiac operations get AF (Hogue 2005), whereas only about $3 \%$ of patients in noncardiac operations get AF (Bhave 2012). Nevertheless, although AF after cardiac surgery is associated with a longer stay in hospital, it is not clear whether the long stay is caused by AF or whether both of them are caused 
by other factors which differ between those patients who get AF and those who do not get AF (Levy 2004). Heavy exercise may also increase the risk of AF (Abdulla 2009; Turagam 2012).

Although AF is associated with increased morbidity and mortality, arrhythmia suppression is not necessarily a good surrogate for clinical events of importance. Clinical events such as thromboembolism, new or worsening HF and death should be preferred as primary outcomes in studies on AF treatment (Wyse 2004).

\section{Description of the intervention}

Vitamin $\mathrm{C}$ was identified in the search for the substance which, when deficient in the body, leads to scurvy (Carpenter 1986). This history led to the assumption that the sole physiological function of vitamin $\mathrm{C}$ is to prevent and treat scurvy. Therefore, it is often assumed that higher doses of vitamin $\mathrm{C}$ cannot be beneficial in a person who does not suffer from scurvy. Due to this history, assessing the role of vitamin $\mathrm{C}$ on diseases and conditions other than scurvy is not just an empirical question but also a conceptual issue.

Vitamin C is an antioxidant and therefore the effects of supplementation might occur or might be most pronounced under conditions when there is increased oxidative stress in the body.

Aging leads to an increase in oxidative stress (Toroser 2007; Dai 2009). Therefore, vitamin $C$ might have a different influence on the elderly compared with middle-aged and young people. In a large-scale cancer prevention trial amongst smokers, vitamin $\mathrm{E}$ decreased mortality in the oldest males only if they had high dietary vitamin C intake (Hemilä 2009; Hemilä 2011). This modification was specific to vitamin $C$ and was not explained by other substances in fruit, vegetables or berries (Hemilä 2009). In a meta-analysis of 29 trials, vitamin C was found to reduce blood pressure (Juraschek 2012), but the studies were short and the practical importance of this effect is not clear.

Exercise causes oxidative stress (Powers 2011) which is prevented by vitamin C (Silvestro 2002). Thus, vitamin C might affect people who endure heavy physical stress. In five trials with participants who had short-term heavy physical stress, vitamin C halved the incidence of common cold symptoms, and in three trials with participants who suffered from exercise-induced bronchoconstriction, vitamin $\mathrm{C}$ halved the $\mathrm{FEV}_{1}$ decline caused by exercise (Hemilä 2014).

Infections cause oxidative stress because activated leukocytes release reactive oxygen and nitrogen species (Akaike 2001; Galley 1996); therefore, vitamin C levels are decreased in various infections (Hemilä 2006). Over two dozen trials have shown that vitamin C shortens the duration of colds (Hemilä 2013a) and two trials reported therapeutic benefit for pneumonia patients (Hemilä 2013b).

In randomized trials with critically ill intensive care unit (ICU) patients, vitamin C (Tanaka 2000) and the combination of vitamins C and E (Nathens 2002) significantly decreased the length of mechanical ventilation. In a case-control study, ICU patients who were given vitamins $\mathrm{C}$ and $\mathrm{E}$ and selenium had shorter ICU stays and lower mortality rates (Collier 2008).

Low vitamin $\mathrm{C}$ intakes are not just of historical interest. Cases of scurvy are being reported even nowadays (Holley 2011; Smith 2011) and a survey in a French geriatric acute care ward estimated that about $10 \%$ of patients had clinical symptoms of scurvy ( Raynaud-Simon 2010). In the UK, $25 \%$ of men and $16 \%$ of women from low-income populations had vitamin C deficiency (<11 $\mu \mathrm{mol} / \mathrm{L}$ ) (Mosdøl 2008), and in the USA, 7\% of healthy middle-class participants of a survey had vitamin C deficiency (Schleicher 2009). Thus, if low intakes of vitamin C might provide less protection against oxidative stress and thereby might increase the risk of AF, this issue could be important in substantial segments of Western countries.

Approximately $10 \mathrm{mg} /$ day of vitamin C prevents scurvy but the safe dose range extends to grams per day (Hemilä 2006; IOM 2000). In the US nutritional recommendations, the 'tolerable upper intake level' is stated to be $2 \mathrm{~g} /$ day for adults. However, the basis for this upper limit is the appearance of diarrhoea (IOM 2000) which is a trivial adverse effect that disappears quickly with a reduction in intake. In a pharmacokinetic study, participants were administered up to 100 grams of vitamin $C$ intravenously within a few hours without any reported adverse effects, indicating the safety of such a very large dose in healthy people (Padayatty 2004). Two large-scale trials with 8171 female health professionals and 14,641 male physicians found no adverse effects of $0.5 \mathrm{~g} /$ day of vitamin $\mathrm{C}$ when administered for 8 to 9 years indicating long term safety of such a dosage level (Cook 2007; Sesso 2008).

Finally, vitamin $\mathrm{C}$ is cheap and costs pennies per gram. Therefore, its effects are interesting even if the size of the effect might not be very large.

\section{How the intervention might work}

AF is associated with oxidative stress (Korantzopoulos 2007), and it seems that the cause-effect relation works in both directions. There is much evidence from animal studies that tachycardia (rapid heart rate) leads to oxidative stress. In the hearts of dogs artificially kept at rapid ventricular pacing at $240 \mathrm{bpm}$, the production of superoxide (Ide 1999) and hydroxyl radical (Ide 2000) is increased. In addition, in tachycardic dogs the atrial content of nitrotyrosine was increased and vitamin C level was decreased (Carnes 2001). In rabbits, rapid cardiac pacing increased myocardial oxidative stress as evidenced by the increase in the ratio of oxidized to reduced glutathione and increased level of oxidized mitochondrial DNA (Shite 2001). In pig hearts, experimentally initiated AF increased superoxide production (Dudley 2005). Thus, high cardiac rate appears to cause oxidative stress.

Oxidative stress may, in turn, increase the susceptibility of the heart to tachycardia. In the isolated hearts of aged rats and middleaged rabbits, hydrogen peroxide exposure increased susceptibility 
to ventricular tachycardia, whereas in young rats and rabbits it did not cause tachycardia (Morita 2009). Oxidative stress is elevated in several conditions which increase AF risk, such as age (Dai 2009), coronary artery bypass graft (CABG) surgery (De Vecchi 1998), hypertension (Montezano 2012) and exercise (Powers 2011), and could thus play a role in the emergence of AF.

In humans with $\mathrm{AF}$, oxidative stress was indicated by the increase in the ratio of oxidized to reduced glutathione (Neuman 2007), and decrease in myofibrillar creatine kinase (MM-CK) activity which was inactivated by nitration (Mihm 2001). In the atria of human AF patients the expression of five genes related to the generation of oxidants was increased whereas the expression of two genes related to antioxidants was decreased (Kim 2003). A major source of superoxide in the heart is NADPH oxidase (Montezano 2012), the activity of which was increased in the right atrial appendage of AF patients compared with patients who were in sinus rhythm (SR) (Kim 2005). Although these correlations in human observational studies indicate association between oxidative stress and AF, the direction of cause is undetermined. Nevertheless, in a further study, high atrial NADPH oxidase level predicted postoperative AF (Kim 2008), which implies that oxidative stress preceded AF. Several ion channels expressed in the atria are sensitive to the redox state and, therefore, oxidative stress and antioxidants might influence the electrophysiology of atria (Van Wagoner 2008).

Superoxide reacts with nitric oxide to produce peroxynitrite, a strong oxidant. Vitamin C reacts with superoxide (Nishikimi 1975) and with radicals produced by peroxynitrite (Kirsch 2000) and it might thereby influence AF. In tachycardic dogs, vitamin C prevented the increase in nitrotyrosine levels (Carnes 2001). Another study with tachycardic dogs found that the antioxidant $\mathrm{N}$-acetylcysteine (NAC) enhanced recovery of contractile function after a rapid pacing period (Gare 2002).

In a randomized trial on patients undergoing $\mathrm{CABG}$ or valve surgery (or both), administration of NAC decreased the incidence of postoperative AF (Ozaydin 2008). The combination of vitamins $\mathrm{C}$ and $\mathrm{E}$ with omega-3 fatty acid decreased postoperative AF significantly in two studies (Rodrigo 2012; Rodrigo 2013), and nonsignificantly in a third study (Castillo 2011). The combination of vitamins $\mathrm{C}$ and $\mathrm{E}$ with allopurinol decreased the occurrence of postoperative arrhythmia in CABG patients (Sisto 1995). In a case-control study, the incidence of postoperative AF was lower in CABG patients administered vitamin C (Carnes 2001). Thus, antioxidants might have an effect on the risk of postoperative AF. It is possible that vitamin $\mathrm{C}$ has different effects on different forms of AF. For example, it seems probable that the effect of vitamin C might be greater on paroxysmal than on permanent $\mathrm{AF}$. It seems also probable that vitamin $\mathrm{C}$ has different effects depending on the etiology of AF.

\section{Why it is important to do this review}

$\mathrm{AF}$ is the most common of the serious cardiac rhythm disturbances and vitamin $\mathrm{C}$ is a safe and inexpensive essential nutrient. The possibility that vitamin $\mathrm{C}$ might have preventive or therapeutic effects against $\mathrm{AF}$, even in restricted population groups, is worth examination. A previous meta-analysis focused on the antiarrhythmic effects of antioxidants following cardiac surgery (Harling 2011), but further studies on vitamin $\mathrm{C}$ and $\mathrm{AF}$ have been published since then. The benefit of Cochrane reviews is that they can be kept up to date when new trials are published. In addition, the Harling 2011 review was restricted to studies related to cardiac surgery. No previous Cochrane review has examined the topic of this protocol.

\section{O B J E C T I VES}

To assess the efficacy of vitamin $\mathrm{C}$ for treating AF, and for the secondary prevention of AF.

\section{METHODS}

\section{Criteria for considering studies for this review}

\section{Types of studies}

We will include randomized controlled trials.

For secondary prevention trials, the use of placebo in the control group will not be required as it seems unlikely that being aware of taking or not taking vitamin $\mathrm{C}$ would influence the occurrence of AF. A recent meta-analysis of trials comparing a placebo group with a no treatment group found evidence that the placebo effect on binary outcomes is small at best (Hrobjartsson 2010). Thus, there is no empirical evidence indicating that the placebo effect might substantially influence the type of outcome as the occurrence of AF.

For treatment trials on the incidence of embolic events and return to SR, the use of placebo in the control group will not be required given the above reasoning. In treatment trials reporting on the duration of hospitalization and the incidence of HF associated with AF, we will restrict these to placebo controlled trials, since it is possible that the lack of placebo might bias observations on such outcomes.

We will include trials reported as full-text or abstract, and we will include trials that are unpublished if we get the data. We will study the influence of methodologically less satisfactory trials by sensitivity analysis. 


\section{Types of participants}

\section{Secondary prevention}

We will include trials with people of any age who do not have AF at the baseline, but who have had AF or who have a particularly high risk of AF.

\section{Treatment}

We will include trials with people of any age who have AF. We will include studies with all types of AF.

\section{Types of interventions}

The intervention considered is oral or intravenous administration of vitamin $\mathrm{C}$ (ascorbic acid or its salts). We do not set a lower limit to the dose of vitamin $\mathrm{C}$ or to the duration of vitamin $\mathrm{C}$ supplementation.

The primary focus in this review is on the comparison of vitamin $\mathrm{C}$ against a control group with or without placebo, so that all cointerventions are equal in the trial arms. Nevertheless, trials comparing vitamin $\mathrm{C}$ against standard AF drugs will also be included.

\section{Types of outcome measures}

\section{Primary outcomes}

1. Secondary prevention trials: incidence of AF.

2. Treatment trials: incidence of embolic events.

3. Treatment trials: incidence of new HF and worsening of existing HF.

4. All cause mortality.

5. Adverse effects.

\section{Secondary outcomes}

1. Treatment trials: return to SR.

If there are data on the effect of vitamin $\mathrm{C}$ on quality of life and economic costs, they will be described.

Adverse events reported in the trials will be collected, but it is unlikely that the trials on AF are informative on this issue, given the findings in previous large-scale trials with follow-ups of several years duration (Cook 2007; Sesso 2008) and in short studies with particularly high vitamin C doses (e.g. Padayatty 2004) and other extensive literature on vitamin C safety (Hemilä 2006; IOM 2000).

\section{Search methods for identification of studies}

\section{Electronic searches}

We will identify trials through systematic searches of the following bibliographic databases:

- Cochrane Central Register of Controlled Trials

(CENTRAL) in The Cochrane Library, latest issue;

- MEDLINE (Ovid);

- EMBASE (Ovid).

The search strategy for MEDLINE (Ovid) (Appendix 1) will be adapted for use in the other databases. We will not use filters, but we will hand pick trials fulfilling our inclusion criteria.

We will also conduct a search of ClinicalTrials.gov ( www.ClinicalTrials.gov) and the WHO International Clinical Trials Registry Platform (ICTRP) Search Portal (http://apps.who.int/ trialsearch/).

We will search all databases from their inception to the present, and we will impose no restriction on the language of publication. We will use the Web of Science 'cited reference search' to identify papers that have cited the included trials as a way to check that no relevant studies are missed, e.g. because of miscoding of publications.

\section{Searching other resources}

We will check reference lists of all included trials and relevant review articles for additional references. We will contact authors of published studies to ask if they know of ongoing or unpublished trials.

\section{Data collection and analysis}

\section{Selection of studies}

Two authors (HH, TS) will independently screen titles and abstracts for inclusion of the potential trials identified in the literature search, and will code them as 'retrieve' (eligible or potentially eligible) or 'do not retrieve'. If there are disagreements between the two authors at this stage, the full paper will be retrieved. We will retrieve the full-text trial reports and abstracts, and two authors $(\mathrm{HH}, \mathrm{TS})$ will independently screen the reports and identify trials for inclusion, and record reasons for exclusion of the ineligible studies. Similarly, if we find potentially relevant unpublished results, the two authors will independently consider their inclusion. We will resolve any disagreements through discussion. We will identify duplicate reports and collate multiple reports of the same trial so that the unit of interest is the trial. We will record the selection process in sufficient detail to complete a PRISMA flow diagram and 'Characteristics of excluded studies' table. 


\section{Data extraction and management}

We will use a data collection form for trial characteristics and outcome data which has been piloted on at least one trial in the review. One author $(\mathrm{HH})$ will extract study characteristics from included trials and another author (TS) will confirm the extraction. We will extract the following study characteristics.

1. Methods: study design, total duration of the trial, details of any 'run in' period, trial setting, withdrawals, and date of trial.

2. Participants: N, mean age, age range, gender, severity of condition, diagnostic criteria, inclusion criteria, and exclusion criteria.

3. Interventions: intervention, comparison, concomitant medications, and excluded medications.

4. Outcomes: primary and secondary outcomes of the trial, and time points reported.

5. Potential conflicts of interest: funding for trial and other potential conflicts of interest of trial authors.

6. Additional notes.

Two authors (HH, TS) will independently extract outcome data from included trials. If an included trial does not report data in such a way that it can be included in statistical analyses, the results will be narratively described in the Results section. We will resolve disagreements by discussion. One author $(\mathrm{HH})$ will transfer data into Review Manager 5 (RevMan 2012). The second author (TS) will check the entered results against the original trial reports. We will contact authors to ask for more data when needed. If data are not reported in a way that they can be included in the statistical analyses, we will try to contact the authors to obtain the data in a different form. The outcome of the contacts will be reported.

\section{Assessment of risk of bias in included studies}

Two authors (HH, TS) will independently assess risk of bias for each trial using the criteria outlined in the Cochrane Handbook for Systematic Reviews of Interventions (Higgins 2011). We will resolve any disagreements by discussion. We will assess the risk of bias according to the following domains.

1. Random sequence generation.

2. Allocation concealment.

3. Blinding of participants and personnel.

4. Blinding of outcome assessment.

5. Incomplete outcome data.

6. Selective outcome reporting.

7. Other bias.

We will grade each potential source of bias as high, low or unclear and provide a quote from the trial report together with a justification for our judgment in the 'Risk of bias' table. We will summarize the risk of bias judgements across different trials for each of the domains listed. Where information on risk of bias relates to unpublished data or correspondence with a trialist, we will note this in the 'Risk of bias' table.
When considering intervention effects, we will take into account the risk of bias for the trials which contribute to that outcome.

\section{Measures of treatment effect}

We will analyze dichotomous data as risk ratios (RR) with $95 \%$ confidence intervals (CI) and continuous data as percentage effects with the $95 \%$ CI. We will present the results in forest plots with a consistent direction so that left from the control level means benefit of intervention.

If an included trial does not report data in such a way that it can be presented in a forest plot, the results will be narratively described in the Results section.

Where multiple trial arms are reported in a single trial, we will include only the relevant arms. If several arms are relevant, we will divide the control group between the intervention arms evenly so that the control participants are not double counted.

If only a few positive cases are observed for binary outcomes, the mid-P value will be used to calculate the P values for the differences between the treatment groups (Hemilä 2006; Lydersen 2009).

We will analyze participants in the groups in which they were allocated. We will not impute outcome values for participants lost to follow-up.

We will use two-tailed $\mathrm{P}$ values in this review.

\section{Dealing with missing data}

We will contact investigators to verify key study characteristics and obtain missing outcome data when necessary (e.g. when a trial is identified as abstract only). If we do not get relevant data, we will explore the impact of such trials by a sensitivity analysis.

\section{Assessment of heterogeneity}

We will use the $\mathrm{Chi}^{2}$ test and the $\mathrm{I}^{2}$ statistic to assess statistical heterogeneity among the trials in each meta-analysis (Higgins 2003). A value of $I^{2}$ greater than about $70 \%$ indicates a high level of heterogeneity. If we identify substantial statistical heterogeneity we will report it and explore possible causes by subgroup analyses.

\section{Assessment of reporting biases}

We will construct and report funnel plots for the meta-analyses, although they have been criticized as a tool for assessing whether there is publication bias or not (Ioannidis 2007; Lau 2006; Sterne 2011; Terrin 2005). We follow the instructions of the Cochrane Handbook for Systematic Reviews of Interventions: "Results from tests for funnel plot asymmetry should be interpreted cautiously. When there is evidence of small-study effects, publication bias should be considered as only one of a number of possible explanations. In these circumstances, review authors should attempt to understand the source of the small-study effects, and consider their implications in sensitivity analyses." (Higgins 2011). 
We will also narratively consider the possibility of publication bias in the Discussion section.

\section{Data synthesis}

If a group of trials is clinically sufficiently uniform in settings and outcome definitions, and there is no substantial statistical heterogeneity between the results, we will pool the data using the fixedeffect model. If the trials are heterogeneous, either statistically or clinically, we will not pool them. Nevertheless, even if heterogeneity prevents pooling of a group of studies, the total evidence for the difference between the vitamin $\mathrm{C}$ and control groups can be tested by the combined $\mathrm{P}$ value (Fisher 1948).

\section{Subgroup analysis and investigation of heterogeneity}

We plan to present different conditions of AF separately as subgroups, such as AF related to cardiovascular surgery, recurrent $\mathrm{AF}$ after cardioversion, etc. If there are suitable data available, we are interested in the potential role of age, sex, vitamin C status (important, but rarely reported), and dosage of vitamin $\mathrm{C}$ as subgroup variables. If we present subgroups, we plan to test subgroup interactions in Review Manager (RevMan 2012).

\section{Sensitivity analysis}

We will carry out sensitivity analyses by only including trials with a low risk of bias in all of the following items: random sequence generation, allocation concealment, blinding of participants, personnel and outcome assessment, and incomplete outcome data.

\section{ACKNOW LEDGEMENTS}

The background and methods section of this protocol is based on the standard template used by Cochrane Heart Group.

\section{R E F E R E N C E S}

\section{Additional references}

\section{Abdulla 2009}

Abdulla J, Nielsen JR. Is the risk of atrial fibrillation higher in athletes than in the general population? A systematic review and meta-analysis. Europace 2009;11(9):1156-9. [DOI: 10.1093/europace/eup197; PUBMED: 19633305]

\section{Akaike 2001}

Akaike T. Role of free radicals in viral pathogenesis and mutation. Reviews in Medical Virology 2001;11(2):87-101. [DOI: 10.1002/rmv.303; PUBMED: 11262528]

Bhave 2012

Bhave PD, Goldman LE, Vittinghoff E, Maselli J, Auerbach A. Incidence, predictors, and outcomes associated with postoperative atrial fibrillation after major noncardiac surgery. American Heart Journal 2012;164(6):918-24. [DOI: 10.1016/j.ahj.2012.09.004; PUBMED: 23194493]

\section{Carnes 2001}

Carnes CA, Chung MK, Nakayama T, Nakayama H, Baliga RS, Piao $S$, et al. Ascorbate attenuates atrial pacing-induced peroxynitrite formation and electrical remodeling and decreases the incidence of postoperative atrial fibrillation. Circulatory Research 2001;89(6):E32-8. [DOI: 10.1161/ \%E2\%80\%8Bhh1801.097644; PUBMED: 11557745]

\section{Carpenter 1986}

Carpenter KJ. The History of Scurvy and Vitamin C. Cambridge: Cambridge University Press, 1986.

Castillo 2011

Castillo R, Rodrigo R, Perez F, Cereceda M, Asenjo R, Zamorano J, et al. Antioxidant therapy reduces oxidative and inflammatory tissue damage in patients subjected to cardiac surgery with extracorporeal circulation. Basic and Clinical Pharmacology and Toxicology 2011;108(4):256-62. [DOI: 10.1111/j.1742-7843.2010.00651.x; PUBMED: 21138533]

\section{Collier 2008}

Collier BR, Giladi A, Dossett LA, Dyer L, Fleming SB, Cotton BA. Impact of high-dose antioxidants on outcomes in acutely injured patients [comment in: 2009;33(4):4478]. JPEN. Journal of Parenteral and Enteral Nutrition 2008; 32(4):384-8. [DOI: 10.1177/0148607108319808; DOI: 10.1177/0148607108328520; PUBMED: 18596309; PUBMED: 19229041]

Cook 2007

Cook NR, Albert CM, Gaziano JM, Zaharris E, MacFadyen J, Danielson E, et al. A randomized factorial trial of vitamins $\mathrm{C}$ and $\mathrm{E}$ and beta carotene in the secondary prevention of cardiovascular events in women: results from the Women's Antioxidant Cardiovascular Study. Archives of Internal Medicine 2007;167(15):1610-8. [DOI: 10.1001/ archinte.167.15.1610; PUBMED: 17698683]

Dai 2009

Dai DF, Rabinovitch PS. Cardiac aging in mice and humans: the role of mitochondrial oxidative stress. Trends in Cardiovascular Medicine 2009;19(7):213-20. [DOI: 10.1016/j.tcm.2009.12.004; PUBMED: 20382344]

De Vecchi 1998

De Vecchi E, Pala MG, Di Credico G, Agape V, Paolini G, Bonini PA, et al. Relation between left ventricular function and oxidative stress in patients undergoing bypass surgery. Heart 1998;79(3):242-7. [DOI: 10.1136/hrt.79.3.242; PUBMED: 9602656] 
Dudley 2005

Dudley SC Jr, Hoch NE, McCann LA, Honeycutt C, Diamandopoulos L, Fukai T, et al. Atrial fibrillation increases production of superoxide by the left atrium and left atrial appendage: role of the NADPH and xanthine oxidases. Circulation 2005;112(9):1266-73. [DOI: 10.1161/ \%E2\%80\%8BCIRCULATIONAHA.105.538108; PUBMED: 16129811]

Fisher 1948

Fisher RA. Combining independent tests of significance. American Statistician 1948;2(5):30-1. [DOI: 10.2307/ 2681650]

Galley 1996

Galley HF, Davies MJ, Webster NR. Ascorbyl radical formation in patients with sepsis: effect of ascorbate loading. Free Radicals in Biology and Medicine 1996;20 (1):139-43. [DOI: 10.1016/0891-5849(95)02022-5; PUBMED: 8903690]

\section{Gare 2002}

Gare M, Mraovic B, Kehl F, Kersten JR, Warltier DC, Pagel PS. Reactive oxygen species contribute to contractile dysfunction following rapid ventricular pacing in dogs. International Journal of Cardiology 2002;83(2):125-31. [DOI: 10.1016/S0167-5273(02)00030-X; PUBMED: 12007684]

Go 2001

Go AS, Hylek EM, Phillips KA, Chang Y, Henault LE, Selby JV, et al. Prevalence of diagnosed atrial fibrillation in adults: national implications for rhythm management and stroke prevention: the AnTicoagulation and Risk Factors in Atrial Fibrillation (ATRIA) Study. JAMA 2001;285(18): 2370-5. [DOI: 10.1001/jama.285.18.2370; PUBMED: 11343485]

Harling 2011

Harling L, Rasoli S, Vecht JA, Ashrafian H, Kourliouros A, Athanasiou T. Do antioxidant vitamins have an antiarrhythmic effect following cardiac surgery? A metaanalysis of randomised controlled trials. Heart 2011;97 (20):1636-42. [DOI: 10.1136/heartjnl-2011-300245; PUBMED: 21865202]

\section{Hemilä 2006}

Hemilä H. Do vitamins C and E affect respiratory infections? [Dissertation]. University of Helsinki, Helsinki, Finland 2006:6-7, 20-1, 62-3. [http://hdl.handle.net/ 10138/20335; https://oa.doria.fi/handle/10024/1540]

\section{Hemilä 2009}

Hemilä H, Kaprio J. Modification of the effect of vitamin E supplementation on the mortality of male smokers by age and dietary vitamin C. American Journal of Epidemiology 2009;169(8):946-53. [DOI: 10.1093/aje/kwn413; PUBMED: 19218294]

Hemilä 2011

Hemilä H, Kaprio J. Vitamin E may affect the life expectancy of men, depending on dietary vitamin $\mathrm{C}$ intake and smoking. Age and Ageing 2011;40(2):215-20. [DOI: 10.1093/ageing/afq178; PUBMED: 21242192]

\section{Hemilä 2013a}

Hemilä H, Chalker E. Vitamin C for preventing and treating the common cold. Cochrane Database of Systematic Reviews 2013, Issue 1. [DOI: 10.1002/ 14651858.CD000980.pub4; PUBMED: 23440782]

\section{Hemilä 2013b}

Hemilä H, Louhiala P. Vitamin C for preventing and treating pneumonia. Cochrane Database of Systematic Reviews 2013, Issue 8. [DOI: 10.1002/14651858.CD005532.pub3]

\section{Hemilä 2014}

Hemilä $\mathrm{H}$. The effect of vitamin $\mathrm{C}$ on bronchoconstriction and respiratory symptoms caused by exercise: a review and statistical analysis. Allergy, Asthma \& Clinical Immunology 2014;10:58. [DOI: 10.1186/1710-1492-10-58; PUBMED: ]

\section{Higgins 2003}

Higgins JPT, Thompson SG, Deeks JJ, Altman DG. Measuring inconsistency in meta-analysis. BMJ 2003; 327(7414):557-60. [DOI: 10.1136/bmj.327.7414.557; PUBMED: 12958120 ]

\section{Higgins 2011}

Higgins JPT, Green S (editors). Cochrane Handbook for Systematic Reviews of Interventions Version 5.1 [updated March 2011]. The Cochrane Collaboration, 2011. Available at www.cochrane-handbook.org.

\section{Hogue 2005}

Hogue CW Jr, Creswell LL, Gutterman DD, Fleisher LA, American College of Chest Physicians. Epidemiology, mechanisms, and risks: American College of Chest Physicians guidelines for the prevention and management of postoperative atrial fibrillation after cardiac surgery. Chest 2005;128(2 Suppl):9S-16S. [DOI: 10.1378/chest.128.2 suppl.9S; PUBMED: 16167659]

\section{Holley 2011}

Holley AD, Osland E, Barnes J, Krishnan A, Fraser JF. Scurvy: historically a plague of the sailor that remains a consideration in the modern intensive care unit. Internal Medicine Journal 2011;41(3):283-5. [DOI: 10.1111/ j.1445-5994.2010.02413.x; PUBMED: 21426466]

\section{Hrobjartsson 2010}

Hrobjartsson A, Gotzsche PC. Placebo interventions for all clinical conditions. Cochrane Database of Systematic Reviews 2010, Issue 1. [DOI: 10.1002/ 14651858.CD003974.pub3]

\section{Ide 1999}

Ide T, Tsutsui H, Kinugawa S, Utsumi H, Kang D, Hattori $\mathrm{N}$, et al. Mitochondrial electron transport complex I is a potential source of oxygen free radicals in the failing myocardium. Circulatory Research 1999;85(4):357-63. [DOI: 10.1161/01.RES.85.4.357; PUBMED: 10455064]

\section{Ide 2000}

Ide T, Tsutsui H, Kinugawa S, Suematsu N, Hayashidani $S$, Ichikawa K, et al. Direct evidence for increased hydroxyl radicals originating from superoxide in the failing myocardium. Circulatory Research 2000;86(2):152-7. [10.1161/ 01.RES.86.2.152; PUBMED: 10666410] 


\section{Ioannidis 2007}

Ioannidis JP, Trikalinos TA. The appropriateness of asymmetry tests for publication bias in meta-analyses: a large survey. CMAJ : Canadian Medical Association Journal 2007;176(8):1091-6. [DOI: 10.1503/cmaj.060410; PUBMED: 17420491]

\section{IOM 2000}

Institute of Medicine. Vitamin C. Dietary reference intakes for vitamin $C$, vitamin $E$, selenium and carotenoids. Washington DC: National Academy Press, 2000:95-185. [http://www.nap.edu/openbook.php?record_id=9810\& page $=95]$

Iqbal 2005

Iqbal MB, Taneja AK, Lip GY, Flather M. Recent developments in atrial fibrillation. BMJ 2005;330(7485): 238-43. [DOI: 10.1136/bmj.330.7485.238; PUBMED: 15677659]

Juraschek 2012

Juraschek SP, Guallar E, Appel LJ, Miller ER 3rd. Effects of vitamin $\mathrm{C}$ supplementation on blood pressure: a metaanalysis of randomized controlled trials. American Journal of Clinical Nutrition 2012;95(5):1079-88. [DOI: 10.3945/ ajcn.111.027995; PUBMED: 22492364]

\section{Kannel 1998}

Kannel WB, Wolf PA, Benjamin EJ, Levy D. Prevalence, incidence, prognosis, and predisposing conditions for atrial fibrillation: population-based estimates. American Journal of Cardiology 1998;82(8A):2N-9N. [DOI: 10.1016/ S0002-9149(98)00583-9; PUBMED: 9809895]

Kim 2003

Kim YH, Lim DS, Lee JH, Shim WJ, Ro YM, Park GH, et al. Gene expression profiling of oxidative stress on atrial fibrillation in humans. Experimental and Molecular Medicine 2003;35(5):336-49. [DOI: 10.1038/emm.2003.45; PUBMED: 14646586$]$

Kim 2005

Kim YM, Guzik TJ, Zhang YH, Zhang MH, Kattach $\mathrm{H}$, Ratnatunga $\mathrm{C}$, et al. A myocardial Nox2 containing $\mathrm{NAD}(\mathrm{P}) \mathrm{H}$ oxidase contributes to oxidative stress in human atrial fibrillation. Circulatory Research 2005;97(7): 629-36. [DOI: 10.1161/01.RES.0000183735.09871.61; PUBMED: 16123335]

Kim 2008

Kim YM, Kattach H, Ratnatunga C, Pillai R, Channon $\mathrm{KM}$, Casadei B. Association of atrial nicotinamide adenine dinucleotide phosphate oxidase activity with the development of atrial fibrillation after cardiac surgery. Journal of the American College of Cardiology 2008;51(1): 68-74. [DOI: 10.1016/j.jacc.2007.07.085; PUBMED: 18174039]

\section{Kirchof 2012}

Perk J, De Backer G, Gohlke H, Graham I, Reiner Z, Verschuren M, et al. European Guidelines on cardiovascular disease prevention in clinical practice (version 2012). European Heart Journal 2012;33(13):1635-701. [DOI: 10.1093/eurheartj/ehs092; PUBMED: 22555213]

\section{Kirsch 2000}

Kirsch M, de Groot H. Ascorbate is a potent antioxidant against peroxynitrite-induced oxidation reactions. Evidence that ascorbate acts by re-reducing substrate radicals produced by peroxynitrite. Journal of Biological Chemistry 2000; 275(22):16702-8. [DOI: 10.1074/jbc.M909228199; PUBMED: 10748119]

\section{Korantzopoulos 2007}

Korantzopoulos P, Kolettis TM, Galaris D, Goudevenos JA. The role of oxidative stress in the pathogenesis and perpetuation of atrial fibrillation. International Journal of Cardiology 2007;115(2):135-43. [DOI: 10.1016/ j.ijcard.2006.04.026; PUBMED: 16764958]

\section{Kozlowski 2009}

Kozlowski D, Budrejko S, Lip GY, Rysz J, Mikhailidis DP, Raczak G, Banach M. Lone atrial fibrillation: what do we know?. Heart 2010;96(7):498-503. [DOI: 10.1136/ hrt.2009.176321; PUBMED: 19713203]

\section{Lau 2006}

Lau J, Ioannidis JP, Terrin N, Schmid CH, Olkin I. The case of the misleading funnel plot. BMJ 2006;333(7568): 597-600. [DOI: 10.1136/bmj.333.7568.597; PUBMED: 16974018]

\section{Levy 2004}

Levy D, Kannel WB. Postoperative atrial fibrillation and mortality: do the risks merit changes in clinical practice? . Journal of the American College of Cardiology 2004;43(5): 749-51. [DOI: 10.1016/j.jacc.2003.12.011; PUBMED: 14998611]

Lip 2012

Lip GY, Tse HF, Lane DA. Atrial fibrillation. Lancet 2012;379(9816):648-61. [DOI: 10.1016/S0140-6736 (11)61514-6; PUBMED: 22166900]

\section{Lydersen 2009}

Lydersen S, Fagerland MW, Laake P. Recommended tests for association in $2 \times 2$ tables. Statistics in Medicine 2009; 28(7):1159-75. [DOI: 10.1002/sim.3531; PUBMED: 19170020]

\section{Mihm 2001}

Mihm MJ, Yu F, Carnes CA, Reiser PJ, McCarthy PM, Van Wagoner DR, et al. Impaired myofibrillar energetics and oxidative injury during human atrial fibrillation. Circulation 2001;104(2):174-80. [DOI: 10.1161/01.CIR.104.2.174; PUBMED: 11447082]

\section{Montezano 2012}

Montezano AC, Touyz RM. Oxidative stress, Noxs, and hypertension: experimental evidence and clinical controversies [erratum: 44(8):854-8]. Annals of Medicine 2012;44(Suppl 1):S2-S16. [DOI: 10.3109/ 07853890.2011.653393; PUBMED: 22713144]

Morita 2009

Morita N, Sovari AA, Xie Y, Fishbein MC, Mandel WJ, Garfinkel A, et al. Increased susceptibility of aged hearts to ventricular fibrillation during oxidative stress. American Journal of Physiology: Heart and Circulatory Physiology 2009; 
297(5):H1594-605. [DOI: 10.1152/ajpheart.00579; PUBMED: 19767530]

\section{Mosdøl 2008}

Mosdøl A, Erens B, Brunner EJ. Estimated prevalence and predictors of vitamin C deficiency within UK's low-income population. Journal of Public Health 2008;30(4):456-60. [DOI: 10.1093/pubmed/fdn076; PUBMED: 18812436]

\section{Nathens 2002}

Nathens AB, Neff MJ, Jurkovich GJ, Klotz P, Farver $\mathrm{K}$, Ruzinski JT, et al. Randomized, prospective trial of antioxidant supplementation in critically ill surgical patients. Annals of Surgery 2002;236(6):814-22. [http: //www.ncbi.nlm.nih.gov/pmc/articles/PMC1422648/; PUBMED: 12454520]

\section{Neuman 2007}

Neuman RB, Bloom HL, Shukrullah I, Darrow LA, Kleinbaum D, Jones DP, et al. Oxidative stress markers are associated with persistent atrial fibrillation. Clinical Chemistry 2007;53(9):1652-7. [DOI: 10.1373/ clinchem.2006.083923; PUBMED: 17599958]

\section{Nishikimi 1975}

Nishikimi M. Oxidation of ascorbic acid with superoxide anion generated by the xanthine-xanthine oxidase system. Biochemical and Biophysical Research Communications 1975; 63(2):463-8. [DOI: 10.1016/0006-291X(75)90710-X; PUBMED: 235924]

\section{Ozaydin 2008}

Ozaydin M, Peker O, Erdogan D, Kapan S, Turker Y, Varol $\mathrm{E}$, et al. $\mathrm{N}$-acetylcysteine for the prevention of postoperative atrial fibrillation: a prospective, randomized, placebocontrolled pilot study. European Heart Journal 2008;29(5): 625-31. [DOI: 10.1093/eurheartj/ehn011; PUBMED: $18263874]$

\section{Padayatty 2004}

Padayatty SJ, Sun H, Wang Y, Riordan HD, Hewitt SM, Katz A, et al. Vitamin C pharmacokinetics: implications for oral and intravenous use. Annals of Internal Medicine 2004;140(7):533-7. [DOI: 10.7326/ 0003-4819-140-7-200404060-00010; PUBMED: $15068981]$

\section{Page 2004}

Page RL. Newly diagnosed atrial fibrillation. New England Journal of Medicine 2004;351(23):2408-16. [DOI: 10.1056/NEJMcp041956; PUBMED: 15575057]

\section{Powers 2011}

Powers SK, Nelson WB, Hudson MB. Exercise-induced oxidative stress in humans: cause and consequences. Free Radicals in Biology and Medicine 2011;51(5):942-50. [DOI: 10.1016/j.freeradbiomed.2010.12.009; PUBMED: 21167935]

\section{Raynaud-Simon 2010}

Raynaud-Simon A, Cohen-Bittan J, Gouronnec A, Pautas E, Senet P, Verny M, et al. Scurvy in hospitalized elderly patients. Journal of Nutrition, Health and Aging 2010;14(6): 407-10. [DOI: 10.1007/s12603-010-0032-y; PUBMED: 20617280]
RevMan 2012 [Computer program]

The Nordic Cochrane Centre, The Cochrane Collaboration. Review Manager (RevMan). Version 5.2. Copenhagen: The Nordic Cochrane Centre, The Cochrane Collaboration, 2012.

Rodrigo 2012

Rodrigo R, Gutiérrez R, Fernández R, Guzmán P. Ageing improves the antioxidant response against postoperative atrial fibrillation: a randomized controlled trial. Interactive Cardiovascular and Thoracic Surgery 2012;15(2):209-14. [DOI: 10.1093/icvts/ivs154; PUBMED: 22561296]

Rodrigo 2013

Rodrigo R, Korantzopoulos P, Cereceda M, Asenjo $\mathrm{R}$, Zamorano J, Villalabeitia E, et al. A randomized controlled trial to prevent post-operative atrial fibrillation by antioxidant reinforcement. Journal of the American College of Cardiology 2013;62(16):1457-65. [DOI: 10.1016/ j.jacc.2013.07.014; PUBMED: 23916928]

\section{Schleicher 2009}

Schleicher RL, Carroll MD, Ford ES, Lacher DA. Serum vitamin $\mathrm{C}$ and the prevalence of vitamin $\mathrm{C}$ deficiency in the United States: 2003-2004 National Health and Nutrition Examination Survey (NHANES). American Journal of Clinical Nutrition 2009;90(5):1252-63. [DOI: 10.3945/ ajcn.2008.27016; PUBMED: 19675106]

\section{Sesso 2008}

Sesso HD, Buring JE, Christen WG, Kurth T, Belanger C, MacFadyen J, et al. Vitamins $\mathrm{E}$ and $\mathrm{C}$ in the prevention of cardiovascular disease in men: the Physicians' Health Study II randomized controlled trial. JAMA 2008;300(18): 2123-33. [DOI: 10.1001/jama.2008.600; PUBMED: $18997197]$

Shite 2001

Shite J, Qin F, Mao W, Kawai H, Stevens SY, Liang C. Antioxidant vitamins attenuate oxidative stress and cardiac dysfunction in tachycardia-induced cardiomyopathy. Journal of the American College of Cardiology 2001;38 (6):1734-40. [DOI: 10.1016/S0735-1097(01)01596-0; PUBMED: 11704389]

\section{Silvestro 2002}

Silvestro A, Scopacasa F, Oliva G, de Cristofaro T, Iuliano L, Brevetti G. Vitamin C prevents endothelial dysfunction induced by acute exercise in patients with intermittent claudication. Atherosclerosis 2002;165(2):277-83. [DOI: 10.1016/S0021-9150(02)00235-6; PUBMED: 12417278$]$

Sisto 1995

Sisto T, Paajanen H, Metsä-Ketelä T, Harmoinen A, Nordback I, Tarkka M. Pretreatment with antioxidants and allopurinol diminishes cardiac onset events in coronary artery bypass grafting. Annals of Thoracic Surgery 1995; 59(6):1519-23. [DOI: 10.1016/0003-4975(95)00197-S; PUBMED: 7771834

\section{Smith 2011}

Smith A, Di Primio G, Humphrey-Murto S. Scurvy in the developed world. CMAJ : Canadian Medical 
Association Journal 2011;183(11):E752-2. [DOI: 10.1503/ cmaj.091938; PUBMED: 21555388]

\section{Sterne 2011}

Sterne JA, Sutton AJ, Ioannidis JP, Terrin N, Jones DR, Lau $\mathrm{J}$, et al. Recommendations for examining and interpreting funnel plot asymmetry in meta-analyses of randomised controlled trials. BMJ 2011;343:d4002. [DOI: 10.1136/ bmj.d4002; PUBMED: 21784880]

\section{Tanaka 2000}

Tanaka H, Matsuda T, Miyagantani Y, Yukioka T, Matsuda $\mathrm{H}$, Shimazaki S. Reduction of resuscitation fluid volumes in severely burned patients using ascorbic acid administration: a randomized, prospective study. Archives of Surgery 2000; 135(3):326-31. [DOI: 10.1001/archsurg.135.3.326; PUBMED: 10722036]

\section{Terrin 2005}

Terrin N, Schmid CH, Lau J. In an empirical evaluation of the funnel plot, researchers could not visually identify publication bias. Journal of Clinical Epidemiology 2005; 58(9):894-901. [DOI: 10.1016/j.jclinepi.2005.01.006; PUBMED: 16085192]

\section{Toroser 2007}

Toroser D, Sohal RS. Age-associated perturbations in glutathione synthesis in mouse liver. Biochemical Journal
2007;405(3):583-9. [DOI: 10.1042/BJ20061868; PUBMED: 17461778]

\section{Turagam 2012}

Turagam MK, Velagapudi P, Kocheril AG. Atrial fibrillation in athletes. American Journal of Cardiology 2012;109

(2):296-302. [DOI: 10.1016/j.amjcard.2011.08.041; PUBMED: 22019138]

Van Wagoner 2008

Van Wagoner DR. Oxidative stress and inflammation in atrial fibrillation: role in pathogenesis and potential as a therapeutic target. Journal of Cardiovascular Pharmacology 2008;52(4):306-13. [DOI: 10.1097/ FJC.0b013e31817f9398; PUBMED: 18791466]

Wang 2003

Wang TJ, Larson MG, Levy D, Vasan RS, Leip EP, Wolf PA, et al. Temporal relations of atrial fibrillation and congestive heart failure and their joint influence on mortality: the Framingham Heart Study. Circulation 2003;107(23): 2920-4. [DOI: 10.1161/01.CIR.0000072767.89944.6E; PUBMED: 12771006]

\section{Wyse 2004}

Wyse DG. Overview of endpoints in atrial fibrillation studies. Heart Rhythm 2004;1(2 Suppl):B3-7. [DOI: 10.1016/j.hrthm.2004.03.070; PUBMED: 15851133]

* Indicates the major publication for the study

\section{A P P E N D I C E S}

\section{Appendix I. MEDLINE (OVID) draft strategy}

1. Ascorbic Acid/

2. ascorb*.tw.

3. (vit* adj6 c).tw.

4. magnorbin.tw.

5. hybrin.tw.

6. or/1-5

7. Atrial Fibrillation/

8. atrial fibrillation*.tw.

9. auricular fibrillation*.tw.

10. atrium fibrillation*.tw.

11. af.tw.

12. a-fib.tw.

13. or $/ 7-12$

14.6 and 13 


\section{CONTRIBUTIONSOFAUTHORS}

$\mathrm{HH}$ wrote the draft for the protocol.

TS participated in the revision of the draft.

\section{DECLARATIONSOF INTEREST}

None known.

\section{SOURCES OF SUPPORT}

\section{Internal sources}

- New Source of support, Other.

\section{External sources}

- No external funding, Finland. 